\title{
Pensar a vulnerabilidade a partir da ideia de trauma
}

Thinking vulnerability through the idea of trauma

\author{
Cátia Guerra - Universidade do Porto | Porto | Portugal | E-mail: \\ catiaguerra07@gmail.com
}
Resumo: A ideia de trauma, enquanto categoria psiquiátrica, põe em evidência a existência de uma vulnerabilidade comum. O dispositivo psiquiátrico, simultaneamente disciplinar e biopolítico, organiza a vulnerabilidade ao trauma segundo mecanismos de governamentalidade que têm em vista a racionalidade econômica, a segurança da população e a constituição do indivíduo como empreendedor de si próprio. Assim, a vulnerabilidade é sinalizada, diferenciada e qualificada como negativa, de forma a preservar a segurança dos sujeitos e da população. Procura-se neste artigo, fundamentalmente a partir das obras de Michel Foucault e de Alasdair MacIntyre, analisar o dispositivo psiquiátrico no governo da vulnerabilidade e refletir se pode este governo ocorrer de outra forma, em que o reconhecimento da vulnerabilidade e da dependência seja o caminho para construir comunidades com uma diferente partilha do espaço urbano que procurem o bem comum.

Palavras-chave: Trauma. Psiquiatria. Vulnerabilidade. Biopolítica. Bem comum.

Abstract: The concept of trauma, as a psychiatric category, contains in itself the notion of a common vulnerability. Psychiatric power, understood here as a biopolitic and disciplinar dispositive, organizes vulnerability to trauma according to mechanisms of governmentality that aim towards economic rationality, population security and the constitution of the subject as entrepreneur of himself. Vulnerability is signalled, differentiated and framed as something inherently negative, for the purpose of protecting individuals and populations. Basing itself on the works of Michel Foucault and Alasdair MacIntyre, this article aims to analyse the psychiatric dispositive in the government of vulnerability, and gestures towards articulating alternative possibilities in which acknowledgement of a shared vulnerability and mutual dependency could function as a way to build communities with a different sharing of the urban space that strive for a common good.

Keywords: Trauma. Psychiatry. Vulnerability. Biopolitics. Common good.

- Recebido em 07 de maio de 2019 • Aprovado em 24 de junho de 2019 • e-ISSN: 2177-5788

DOI: https://doi.org/10.22484/2177-5788.2019v45n1p71-86

Copyright @ 2019. Conteúdo de acesso aberto, distribuído sob os termos da Licença Internaonal da CreativeCommons - CC BY-NC-SA - Atribuição Não Comercial (https://br.creativecommons.org/licencas/) Permite distribuição e reprodução, desde que atribuam os devido créditos à publicação, ao autor(es) e que licenciem as novas criações sob termos idênticos. 


\section{Da Vulnerabilidade ao Trauma}

A ideia de vulnerabilidade como pertencente à condição humana é uma forma de conceber o sujeito considerando a sua fragilidade e dependência como inevitáveis e universáveis. MacIntyre (1999) relaciona o reconhecimento da vulnerabilidade, que elabora como decorrente de uma identidade corporal, com a aceitação da dependência do outro, defendendo uma vulnerabilidade comum a todos os indivíduos, agravada em situações de doença, escassez e sofrimento. As diferentes configurações da vulnerabilidade como biológica ou social, universal ou situacional, coletiva ou individual, estão associadas a formas de governo do sujeito, através de um poder sobre a vida que a regula, exacerba ou diminui, enquadrando o sujeito vulnerável como sujeito a ser obrigatoriamente protegido ou excluído.

Para Foucault (2009), a biopolítica é este poder regulador da vida e dos seus processos, que tem a população como alvo, a economia política como forma de conhecimento e os dispositivos de segurança como o seu instrumento. Esta nova governamentalidade, uma nova forma de governar a conduta dos sujeitos, é caracterizada pelo reaparecimento da naturalidade, uma naturalidade que diz respeito aos processos entre as pessoas, considerando a sociedade como um processo natural, reduzindo o sujeito a um dado estatístico e a ação ao comportamento. A economia política surge como uma ciência centrada na gestão da população, associada a mecanismos direcionados para a segurança dos processos econômicos, e também para o controlo da perturbação e da irregularidade, estendendo a sua forma de governar o sujeito a outros domínios como a medicina e a psiquiatria.

É neste contexto condicionado pelos princípios de racionalidade econômica e segurança que, no final do século XIX, que segundo Young (1995), emerge a ideia de trauma, enquanto categoria psiquiátrica, partindo da analogia entre o choque cirúrgico, nomeadamente resultante dos acidentes de comboio e o choque nervoso. Este conceito foi se tornando progressivamente mais vasto, abrangendo o abuso sexual, as vivências de guerra e outras situações violentas, tornando evidente a existência de uma vulnerabilidade psíquica comum, a vulnerabilidade a acontecimentos externos. A ideia de acontecimento externo é em si mesmo discutível, pois todo o acontecimento depende de uma dinâmica entre interno e externo, vulnerabilidade e resistência.

Neste trabalho, pretende-se pensar o trauma do ponto de vista do dispositivo psiquiátrico, conforme preconiza a American Psychiatric Association (2013), onde a situação traumática é tecnicamente definida como exposição, direta ou indireta, à morte, lesão grave ou violência sexual, efetiva ou sob a forma de ameaça e é associada a várias categorias 
diagnósticas ${ }^{1}$. Sendo que o seu uso ultrapassa a categoria psiquiátrica e que a sua vulgarização tem vindo a intensificar-se. Hoje, a ideia de trauma significa sobretudo acontecimento violento e súbito que abala o fundamento do que é ser humano, não do ponto de vista da natureza humana que, como diz Arendt (2007), remeteria para algo como o divino, mas do conjunto de valores, memórias, discursos que nos definem como humanos.

O motivo de neste artigo se pensar o trauma enquanto categoria psiquiátrica e não outra forma de adoecer mental, deve-se à relação entre trauma e acontecimento, à massificação do seu uso, à abrangência progressiva de situações consideradas de menor violência ${ }^{2}$ e ao fato de surgir associado a formas de governo centradas nas ideias de risco e segurança. Assim, tendo por base a vulnerabilidade ao adoecer mental, nomeadamente ao trauma, pretende-se analisar como o dispositivo psiquiátrico se inscreve em tecnologias de governo da vulnerabilidade, e quais os riscos e potencialidades do reconhecimento de uma vulnerabilidade comum, partindo principalmente das obras de Michel Foucault e Alasdair MacIntyre.

\section{Governo da Vulnerabilidade}

Para Foucault (2008), o poder disciplinar emergiu nos séculos XVII e XVIII, diferenciando-se do poder soberano, o qual era exercido pontualmente e caracterizado pelo direito de matar. O poder disciplinar é centrado no controle permanente dos corpos individuais, atua nas instituições como, por exemplo, no asilo, na escola e no tribunal, através de tecnologias de distribuição, vigilância e das disciplinas de saber-poder.

O nascimento da psiquiatria no século XVIII, que ocorre com a entrada do saber-poder médico no espaço asilar, é uma forma de poder disciplinar onde a libertação dos alienados coincidiu com a organização da loucura e do louco, segundo Foucault (2005). O asilo, o doente mental era controlado através da vigilância e julgamento permanentes, da confissão, da escrita sobre si, da organização do espaço, do tempo e das ações essenciais à constituição do saber médico e ao processo terapêutico.

Na segunda metade do século XVIII, com a preocupação do controle do estado sobre a população, a importância da higiene pública, as teorias da raça e o aparecimento de regimes socio-biológicos como o nazismo, emerge uma nova tecnologia do poder: a biopolítica ${ }^{3}$. A biopolítica tem

${ }^{1}$ Nomeadamente à perturbação de stress pós-traumático, perturbação estado-limite da personalidade e perturbação dissociativa da identidade.

2 Podendo-se discutir o sistema de avaliação da graduação da violência.

3 O conceito foi requalificado por Michel Foucault, mas está longe de ter uma definição estática ou universal. Partindo da obra de Michel Foucault, Negri e Hardt, distinguem biopolítica de biopoder, em que o biopoder é o poder sobre a vida e a biopolítica, o 
como alvo a população, atua sobre a vida e os processos vitais, nomeadamente através da estatística e da epidemiologia, sendo o momento de entrada da vida no campo político, essencial ao desenvolvimento do capitalismo, conforme Foucault (1976). A população passa a ser considerada um conjunto de fenômenos e a razão econômica. Para Foucault (2009), dá um novo conteúdo e novas formas à racionalidade do estado.

Na medicina, a biopolítica, conforme Foucault (2004), tem por objetivos reduzir a mortalidade infantil, prevenir doenças epidêmicas e endêmicas, impor normas nas condições de vida e cuidados médicos adequados. As duas formas de poder descritas complementam-se no governo da vida: enquanto o poder disciplinar atua sobre o corpo individual, procurando extrair a sua utilidade e docilidade, e ocorre através das instituições, a biopolítica gere o corpo-espécie, como conjunto de processos biológicos, e ocorre através do governo estatal.

A medicina é uma forma de saber-poder que tem poderes estatais e institucionais, atuando sobre a população assim como sobre o indivíduo. Os mecanismos de governo da doença mental ocorrem hoje através de medidas gerais da população como incidência, prevalência, mortalidade, morbilidade, anos de vida perdidos e incapacidade, que permitem também o cálculo do risco de adoecer e do impacto econômico da doença, em que o conhecimento estatístico da população leva à implementação de medidas de saúde pública sobretudo direcionadas para o acesso generalizado aos cuidados de saúde mental, promoção, prevenção e vigilância epidemiológica.

No governo da vulnerabilidade ao trauma, as duas formas de poder, disciplinar e biopolítica, relacionam-se e complementam-se. Perante um acontecimento traumático, são ativados mecanismos gerais de prevenção da doença para intervenção sobre as pessoas que o experienciaram e que são automaticamente consideradas em risco de adoecer, como, por exemplo, através da intervenção em crise e da psicologia de emergência. $A$ partir da identificação de pessoas consideradas particularmente vulneráveis, o poder biopolítico dá lugar ao poder disciplinar, a vulnerabilidade comum é individualizada e privatizada, e a pessoa é orientada para uma consulta individual onde se deve colocar em discurso, constituindo-se como doente de forma a alcançar a cura.

Após o incêndio ocorrido em Pedrogão Grande, no Verão de 2017, durante o qual morreram 64 pessoas, um dos discursos dominantes era a necessidade de intervenção psiquiátrica e psicológica imediata, quer pelos dirigentes políticos quer pelos próprios habitantes ${ }^{4}$. Para além da

poder da vida em resistir e determinar uma outra subjetividade. Para uma introdução ao conceito de biopolítica ver Campbell e Sitze (2013).

4 Ver notícia: "Pedrogão: Habitantes Pedem Mais Psicólogos Nas Aldeias", Público, 2 de Julho de 2017. Disponível em: 
mobilização de equipes de intervenção ocorreu a criação de uma comissão de acompanhamento das vítimas5, com os objetivos de, entre outros, monitorizar e caracterizar a população em risco, antes mesmo de se pensarem as condições de vulnerabilidade da população, não só as que promoveram o incêndio, mas também as que propiciaram a instalação da doença.

Ou seja, perante um acontecimento atroz, ocorre a categorização da população atingida como em risco de adoecer mental e as medidas políticas e médicas são direcionadas para o seu apoio, indissociável da sua vigilância, em que toda a população necessita de ser observada e de se colocar em discurso, criando uma narrativa de teor psicológico sobre o acontecimento. É a partir desta intervenção que ocorre a identificação dos indivíduos considerados com maior vulnerabilidade a adoecer e cujo o acompanhamento pretende reduzir a sua vulnerabilidade, prescrevendo a normalidade do sofrimento e a forma de recuperação da funcionalidade.

Desta forma, o dispositivo psiquiátrico, tendo um efeito de reconhecida importância na elaboração da dor, atua segundo processos de normalização do sujeito, individualização do risco $^{6}$ e psiquiatrização do sofrimento, despolitizando as suas origens ao considerar que este é consequência de características do sujeito, obscurecendo o efeito das práticas e decisões políticas, quer no acontecimento quer na vulnerabilidade da população.

É também através da análise e do conhecimento de si, das suas formas de sentir e de agir, mediados por um terapeuta e fundamentados pelo discurso científico, para Foucault (1997), que o indivíduo se constitui como sujeito. A ideia de trauma surge associada a tecnologias de subjetivação que interferem na relação do self consigo mesmo e com a sociedade, para Vermeulen (2014), articulando uma nova relação com o passado, através da qual o sujeito frequentemente se constitui como um ser em risco, que necessita de ser protegido, e em que a vulnerabilidade é constituída como negativa, privada e não partilhada. Contudo, os caminhos traçados do trauma à subjetividade não são únicos nem homogêneos.

A consideração do trauma enquanto doença está também associada a formas de reconhecimento no espaço público e de reivindicação de direitos, quer através da legitimação do sofrimento em processos

https://www.publico.pt/2017/07/02/sociedade/noticia/pedrogao-habitantes-pedemmais-psicologos-para-as-aldeias-1777698. Acesso em: 8 maio 2019.

5 Despacho n. 0 6837/2017, Diário da República n. ${ }^{\circ}$ 152/2017, Série II de 2017-08-08. Disponível em: https://dre.pt/home/Ldre/107973513/details/5/maximized?serie =II\&parte filter $=31 \&$ dreId $=107963525$. Acesso em: 8 maio 2019.

6 Para Gilson, a ideia de risco e vulnerabilidade são frequentemente usadas de forma idêntica, contudo a ideia de risco contém em si uma ideia negativa de vulnerabilidade. 
individuais (como em processos judiciais e na atribuição de vistos de asilo), quer através da criação de movimentos, associações e de outras formas de ação na comunidade7. Pode-se perguntar que espaço público é este onde, enquanto doença, o acontecimento traumático e o sofrimento associado ganham força de verdade.

Se por um lado, a privatização é um componente central do neoliberalismo em que todo o bem deve ser privatizado de modo a maximizar o seu uso produtivo, e em que o privado incluiu a propriedade, os direitos e as liberdades assim como o risco, os problemas e o sofrimento, por outro lado, a necessidade de segurança expande o público, ou seja, o social, sujeito à vigilância e ao controlo governamental, segundo Hardt e Negri (2009). Enquanto que para Arendt (2007) existe uma equivalência entre a esfera pública e o comum, para Hardt e Negri (2004), os conceitos de público e privado são hoje manifestamente insuficientes.

O público enquanto serviços, espaços e bens geridos pelo poder estatal e pela administração pública não é necessariamente o comum, segundo Harvey (2012), que será o espaço da partilha e da ação política. Se o reconhecimento do trauma enquanto doença pode levar a processos de indemnização e estratégias estatais de tratamento, conjugando uma ideia de validação (epistêmica) com uma ideia de justiça (moral), por outro lado, a categorização sob o signo da doença mantém a ligação entre trauma, vulnerabilidade e doença como problema individual e privado, ainda que de reconhecimento público. Contudo, nesta forma de governo da vulnerabilidade também existe a possibilidade que o espaço da visibilidade se possa tornar um espaço comum, onde a vulnerabilidade seja reconhecida como pertença da condição humana, simultaneamente, fragilidade, doença, resistência e abertura ao outro.

Assim, o enquadramento do trauma segundo o dispositivo psiquiátrico pode ter vários efeitos, alguns dos quais antagônicos: elaboração, validação e certificação do sofrimento, psiquiatrização, despolitização, individualização, patologização das reações ao trauma que não estão de acordo com a resposta emocional esperada ou exclusão destas reações do seu reconhecimento, nomeadamente no campo pericial. Este dispositivo oculta ainda os acontecimentos que não correspondem à situação definida psiquiatricamente como acontecimento traumático, a população que não tem acesso ao dispositivo, matéria que tem sido objeto de política pública colocando em tensão o projeto de psiquiatrização (como forma de governar) com a promoção do acesso à saúde (como combate à desigualdade) e as situações de violência que não resultam necessariamente em doença.

\footnotetext{
7 Por exemplo, no reconhecimento da violência doméstica como doença, segundo Duncan, é considerado que o diagnóstico pode, através de iniciativas locais, ajudar a dar visibilidade, detectar, prevenir e tratar os efeitos emocionais da violência.
} 
Toma-se como exemplo a guerra colonial portuguesa, de 1961 a 1974, durante a qual uma geração de jovens saudáveis foi selecionada e enviada para participar na guerra. Os mais vulneráveis, que pertenciam a classes sociais economicamente desfavorecidas, com menor escolaridade e menos possibilidades de evitar a sua participação na guerra, eram maioritariamente formados como soldados-atiradores, colocados em zonas de conflito intenso e tinham poucas possibilidades de ascender a patentes militares mais altas ou de serem colocados em locais de maior segurança. Os que sobreviveram frequentemente continuaram em ciclos de pobreza e vulnerabilidade, depois de terem a vida interrompida por uma razão de Estado. Uma das formas de verem hoje reconhecida a sua participação na guerra é através do estatuto de Deficiente das Forças Armadas, onde necessitam de se submeter a uma perícia e ser-lhes atribuída uma incapacidade igual ou superior a $30 \%{ }^{8}$, por exemplo, associada à perturbação de estresse pós-traumático.

Neste contexto, a ausência das características clínicas que perfazem um diagnóstico psiquiátrico não equivale à ausência de sofrimento, assim como a ausência de sofrimento psicológico não corresponde à ausência de desigualdade, de injustiça e de eventual responsabilização do Estado. Se a existência do diagnóstico remete para segundo plano a causalidade política, fazendo o sofrimento depender de uma vulnerabilidade individual, a sua não existência, não havendo outras formas de dar a ver, impede um reconhecimento que se impõe. O processo de reconhecimento do trauma pelo dispositivo psiquiátrico pode obliterar a experiência, obscurecendo a sua diversidade e complexidade, e ser usado na diferenciação das vítimas que deve compensar e certificar, conforme Fassin e Reichtman (2009), em que o reconhecimento do dano psíquico não equivale necessariamente à despolitização, sendo um modo específico de cruzar o governo da saúde mental com a uma nova contratualidade político-social.

No governo da vulnerabilidade, está presente a necessidade de manter a segurança da população de forma a evitar o seu adoecer num mundo que é eminentemente perigoso. O dispositivo psiquiátrico é enquadrado em medidas que configuram a vulnerabilidade como negativa e que procuram o seu controlo e redução, estando relacionado com medidas de redução de risco e defesa da população que se irão de seguida abordar.

\footnotetext{
${ }^{8}$ Decreto-Lei n. ${ }^{0}$ 43/76, Diário do Governo n. ${ }^{0}$ 16/1976, Série I de 1976-01-20. Disponível em: https://dre.pt/web/guest/pesquisa/-/search/506028/details/normal?l=1. Acesso em: 8 maio 2019.
} 


\section{População em Risco}

A necessidade de prevenção e segurança leva à introdução de tecnologias de conhecimento e de controle da população que pretendem manter a regulação da vida. A procura de reduzir a aleatoriedade estendese ao governo da saúde, em que através de medidas epidemiológicas se tenciona conhecer os fenómenos, a sua incidência e o risco de acontecerem. Para Foucault (2009), nos dispositivos de segurança o objetivo não é limitar os fenômenos, mas geri-los, regulá-los, mantê-los dentro dos limites sociais e econômicos e numa média que seja considerada ótima para um dado nível de funcionamento.

Tendo em vista a regulação ou a modificação do destino biológico da espécie, os dispositivos de segurança procuram identificar o risco de adoecer para cada indivíduo ou grupo. Castel (1991) refere que ocorreu uma substituição da noção de perigosidade pela noção de risco, dado que a perigosidade contém em si a afirmação de uma qualidade imanente ao sujeito, estabelecendo uma relação entre sintomas atuais e o ato a vir, enquanto o risco é uma combinação de fatores abstratos que analisa a probabilidade da ocorrência de modos indesejáveis de comportamento. Segundo Beck (1992), o risco é a forma sistemática de lidar com o acaso, a insegurança e o perigo. As medidas preventivas, focadas na diminuição do risco, são um novo modo de vigilância que atua sobre toda a população e que podem ser realizadas sem nenhum contato com o sujeito, de forma contínua e automática, através de combinações de dados biográficos, gostos, características e comportamentos.

Se a biopolítica surge intimamente ligada com a estatística, o uso das tecnologias informáticas permite hoje um conhecimento e controlo sistemático da população, que procura regular os acontecimentos aleatórios, como são as situações traumáticas, através de mecanismos gerais e específicos da sua prevenção. As medidas gerais de prevenção do trauma pretendem ser despolitizadas e atuar sobre toda a população, pois toda a população é considerada em risco. Para Esposito (2013), a biopolítica está intimamente ligada ao paradigma da imunização, simultaneamente proteção da comunidade e exclusão do outro, em que as tecnologias de imunização identificam e criam o risco de forma a controlá-lo e proteger a comunidade do trauma do contágio.

Como anteriormente referido, as medidas de prevenção específicas são focadas em populações que sofreram um acontecimento potencialmente traumático e em que todo o dispositivo se ativa e atua identificando as pessoas mais vulneráveis que são direcionadas para um acompanhamento específico, passando da população para o sujeito em risco. A necessidade de segurança implica o uso de medidas de vigilância e intervenção psicológica, centradas no controlo do pensamento e do comportamento, mesmo quando o risco principal não é de adoecer. Ou seja, o sujeito deve conhecer-se, estar alerta e controlar a forma como se comporta, modificando a relação consigo e com os outros, de modo a 
proteger-se9. Estas medidas de vigilância são permanentes, tanto intrínsecas como extrínsecas, em que frequentemente as fronteiras entre clínica e perícia se esbatem 10 . O risco ao adoecer mental está intimamente relacionado com formas de prevenção, sinalização e acompanhamento, que procuram reduzir o sofrimento tendo em vista o retorno à normalidade que é também um retorno à produtividade, em que a segurança da população diz respeito à segurança dos processos económicos, existindo uma relação íntima entre os processos de governo da vulnerabilidade e os mecanismos de racionalidade económica. O risco pode dar lugar à perigosidade, dado que existe a possibilidade do sujeito vulnerável ser, pelos mesmos motivos, um sujeito perigoso, como por exemplo, o sujeito traumatizado que se pode tornar no sujeito traumatizante11, dando origem à aproximação entre a necessidade de segurança e a aspiração reabilitadora ${ }^{12}$.

A subjetividade empreendedora, característica do neoliberalismo, segundo Foucault (2010), em que o sujeito é o seu próprio capital e o seu produtor, está associada à privatização da vulnerabilidade e à responsabilização individual, em que a vulnerabilidade é vista como impeditiva da realização das capacidades e desejos do sujeito. Assim, como conciliar o sujeito empreendedor com o sujeito em risco? Se não há produção de riqueza sem a preocupação com o risco e com a segurança, não há sujeito empreendedor sem o sujeito em risco. O risco deve ser diminuído e vencido para proteger o sujeito e confirmá-lo como autor de si próprio e o valorizado discurso do sobrevivente é o da pessoa que vivenciou o trauma, mas o ultrapassou, recuperando a sua funcionalidade prévia. Nem todos os riscos são considerados negativos existindo riscos que valem a pena ser vividos, para Gilson (2016), nomeadamente os que permitem a confirmação da invulnerabilidade.

Hardt e Negri (2017), reconhecendo a subjetividade decorrente do neoliberalismo, defendem que o sujeito empreendedor é detentor de agencialidade e pode também criar uma subjetividade no sentido oposto, resultante da produção constante do comum, através da qual a segurança

${ }^{9}$ São disso exemplo, as recentes medidas destinadas a defender as crianças de abuso sexual. Em 2014, o Conselho da Europa lançou a campanha "Aqui ninguém toca" destinada a ensinar as crianças e os pais a estarem vigilantes e protegerem-se. Disponível em: http://www.underwearrule.org/default pt.asp. Acesso em: 8 mai. 2019.

10 Como por exemplo no programa Prevent, criado em 2015 no Reino Unido, que tem por objetivo de ajudar os clínicos a sinalizar pessoas "vulneráveis a serem atraídas pelo terrorismo". HM GOVERNMENT (2015), 'Revised Prevent Duty Guidance: For England and Wales'. Disponível em: https://www.gov.uk/government/publications/preventduty-guidance. Acesso em: 8 mai. 2019.

${ }^{11}$ A pessoa com doença mental pode ser considerada imprevisível, violenta e perigosa, para si e para os outros. Freud (2009) definiu a expressão compulsão à repetição como situação em que o sujeito vítima de trauma se colocaria em situações de risco, ou no papel de agressor, de forma a modificar a situação traumática.

12 Como por exemplo no tratamento de agressores sexuais. 
derive não do controlo e da vigilância, mas da liberdade e da cooperação. Contudo, para MacIntyre (1999), a preocupação com a segurança, a centralidade do mercado e o individualismo, características do estado moderno, são incompatíveis com a existência de comunidades onde as relações são constituídas pela partilha do comum. Desta forma, procura-se refletir se poderia outro governo da vulnerabilidade ser possível, de modo a construir o comum e a comunidade a partir da ideia da vulnerabilidade.

\section{Reconhecer uma Vulnerabilidade Comum}

A definição de comunidade é heterogênea e adquire diferentes significados, podendo ser considerada como um conjunto de indivíduos que têm objetivos em comum, que possuem uma subjetividade partilhada, que estão unidos pela repartição da propriedade ou pela obrigação e pela falta ${ }^{13}$. Para MacIntyre (1999), o bem individual depende do bem da comunidade e os bens comuns só podem alcançados na medida em que também são de outros. A ideia de comunidade não é defendida por si só, mas uma comunidade de dar e receber, baseada na prática das virtudes, como a justiça, a coragem e a generosidade, que permita o florescimento dos indivíduos, segundo MacIntyre (1998). Esta ideia de comunidade necessita de um grau elevado de partilha, de uma tradição, de uma linguagem, de modos de deliberação e entendimento, em que o bem comum é um bem material ou imaterial, que contribui para o bem de todos, e que surge da atividade cooperativa e do entendimento partilhado da sua importância. Não é um bem comum universal, mas é variável consoante a comunidade e a tradição. É através da relação com aqueles de quem se depende, que se adquirem as competências e o autoconhecimento que permitem desenvolver as virtudes morais e intelectuais, numa relação recíproca entre o reconhecimento da vulnerabilidade e a aquisição de virtudes14.

Partindo do pensamento aristotélico ${ }^{15}$, Alasdair MacInthyre defende que as virtudes dependem do contexto social e da racionalidade e são essenciais na procura do bem comum. As virtudes proporcionam o desenvolvimento do sujeito como ser independente e racional, voltado para o cuidado do outro, pressupõem uma prática, uma narrativa e uma tradição, e são meios para atingir a realização do ser humano. Assim, existe uma relação íntima entre as virtudes de reconhecimento da vulnerabilidade e de

13 Para Esposito (2010), a comunidade é constituída pela obrigação e o comum não é caracterizado pelo que é próprio, mas pela sua remoção, a qual cria uma falta no sujeito.

${ }^{14}$ As virtudes, para Macintyre (2011), são disposições que sustentam as práticas, que permitem alcançar os seus bens intrínsecos, o autoconhecimento e o conhecimento do bem.

15 Para Aristotle (2004), as virtudes são adquiridas pela prática e o objetivo de cada acção é a eudaimonia (traduzido frequentemente como felicidade ou florescimento). MacIntyre (2011), partilha da concepção teleológica do ser humano, defendendo que o seu florescimento seria o processo que o faz agir segundo uma racionalidade prática independente. 
racionalidade independente, as quais permitem a construção do bem comum e da comunidade.

A ideia de bem comum defendida por Alasdair Macintyre difere da concepção neoliberal que transformou o bem comum em serviços, e partilha alguns aspectos com a ideia de comum de Hardt e Negri (2004), os quais consideram que o comum emerge através de processos sociais e colaborativos de produção de práticas, linguagens, comportamento e desejos, baseado na comunicação entre singularidades 16 . O comum é partilhado, produzido e produtivo e a sua mobilização permite a construção de uma nova subjetividade e novas formas de democracia.

Contudo, em Alasdair MacIntyre há um fundamento ético para a construção do comum, onde subjaz o reconhecimento da vulnerabilidade e a prática das virtudes. De forma a encontrar o bem comum é necessário o entendimento prático e partilhado da relação entre bens, regras e virtudes, para as comunidades se protegerem do estado e da economia de mercado, permitindo a participação de todos, o que só poderia acontecer em comunidades de pequena dimensão, conforme Macintyre (1998). Esta ideia difere em grande medida da proposta de Hardt e Negri (2000), quando definem a multitude como a necessidade de uma cidadania global que desafie o controlo sobre a produção da vida. Como ensaiar a partilha do bem comum em comunidades globais é um caminho que Alasdair MacIntyre deixa por traçar.

A ideia da vulnerabilidade como pertencente à condição humana é partilhada com Ricoeur (1990), em que o mesmo ser humano capaz de ação é o ser humano que sofre quando essa ação é impedida. A vulnerabilidade é condição e limite da ação, conforme Ricoeur (2001), existindo um paradoxo entre vulnerabilidade e autonomia, em que a autonomia é sempre de um ser frágil e vulnerável, detentor de uma vulnerabilidade de si e em relação ao outro. É esta relação com o outro que converge com a ideia de vulnerabilidade de Levinas (1978), segundo a qual a fragilidade do outro surge como um apelo ao qual devemos dar resposta ${ }^{17}$. E ambos, a vulnerabilidade está intimamente ligada à responsabilidade, que para Ricoeur (2003), é simultaneamente a capacidade de responder pelos seus atos e de responder ao outro.

Partindo da concepção de vulnerabilidade de Levinas (2018) e Butler (2014) considera que a vulnerabilidade como exposição ao poder é em si um ato de resistência, em que o sujeito vulnerável não é destituído de

16 Para Hardt e Negri (2009), o conceito de singularidade, ao contrário da identidade, aponta para a multiplicidade: constitutiva de si, na relação com outras singularidades, e no processo de se poder tornar diferente. As singularidades não se dissolvem na unidade da comunidade, mas expressam-se livremente no comum (HARDT; NEGRI, 2009).

17 Para Levinas (2018), o reconhecimento do outro permite-nos sair da posição egoísta e instaurar a comunidade. 
agência, mas resiste e modifica o poder que o governa. Contudo, Butler salienta também os riscos do reconhecimento da precariedade ${ }^{18}$, ao poder conduzir ao sentimento de que cada corpo se encontra potencialmente ameaçado por outros, que são também precários, precipitando formas de dominação, violência e de exploração de populações específicas. Assim, se somos todos vulneráveis, por um lado devemos reconhecer o outro como igual e através dele desenvolver as virtudes que nos permitem protegê-lo, por outro lado, cada um de nós está em risco e deve eliminar o outro. Os efeitos do reconhecimento de uma vulnerabilidade comum dependem do enquadramento com que a vida do outro nos é dada e da forma como a vulnerabilidade é governada. O dispositivo psiquiátrico, relacionado com a forma de governo da vulnerabilidade centrada no indivíduo, no risco e num modelo de subjetividade neoliberal, remete o sujeito para o consultório do psiquiatra, ou dá-o a ver sob o signo da doença, enquadrada como perda, fragilidade e disfunção individual.

Ao contrário de uma sociedade onde se acentuam as diferenças, a proposta de MacIntyre (1998) no reconhecimento de uma vulnerabilidade comum procura conduzir à constatação que a identificação do bem individual, ou seja, a melhor forma de gerir a vida de cada um, é indissociável do melhor modo da comunidade gerir a sua vida. Esta forma de comunidade é por natureza política e é em diferentes tipos de justificação política que as distintas concepções de bem comum se apoiam. $\mathrm{Na}$ sociedade contemporânea, existem dois tipos de justificações que sustentam o governo da população: a economia e a segurança que, como anteriormente referido, estão intimamente relacionadas com a regulação dos processos naturais que permitem a eficiência económica e o governo do sujeito. Contudo, para MacIntyre (1999), a justificação da autoridade política por ela fornecer a ordem social segura, na qual os indivíduos podem seguir os seus fins particulares, é uma concepção individualista e minimalista, insuficiente para a sociedade política florescer. Numa comunidade que floresce existem redes de dar e receber, os cidadãos engajam-se na atividade política e na deliberação do bem comum. Estas redes podem tornar-se estruturas de distribuição desigual do poder e, portanto, há sempre a possibilidade de vitimização e exploração, sendo que o exercício das virtudes deve ser informado pela consciência de como o poder é distribuído e a corrupção do seu uso é possível.

Rorty (1989) entra em diálogo com MacIntyre ao considerar que o reconhecimento das semelhanças quanto à fragilidade e dependência deveria ser mais importante do que o reconhecimento de diferenças de

18 Butler não faz uma distinção explícita entre precariedade e vulnerabilidade e os dois termos são usados de forma idêntica. Analisando a obra de Judith Butler e Gilson considera que vulnerabilidade é um termo de sentido mais amplo (probabilidade de ser afetado), sendo que precariedade é a vulnerabilidade à perda, indo de encontro à ideia de vulnerabilidade de Alasdair MacIntyre. 
gênero, religião, raça e ser motivo de solidariedade. A vulnerabilidade como uma forma de abertura e reconhecimento do outro está subjacente à solidariedade, a qual deveria ser um objetivo a ser atingido não pela investigação ou reflexão, mas pela imaginação, pela capacidade de ver pessoas estranhas como companheiras do sofrimento, através da qual aumentaria a nossa sensibilidade aos detalhes particulares da dor e da humilhação do outro. Tanto para Alasdair MacIntyre como para Richard Rorty, a solidariedade tem uma base ética e não epistemológica ou metafísica e a comunidade seria fundada nas virtudes ou na esperança e confiança partilhadas, respectivamente. Assim, o reconhecimento da vulnerabilidade poderia possibilitar uma outra comunidade e modos de resistência, permitindo a aceitação da diferença e constituindo uma nova forma política de partilhar e experienciar o bem comum.

Contrariamente ao que Alasdair MacIntyre propõe, o governo da vulnerabilidade é centrado na eficiência econômica e na segurança, na estratificação de diferentes níveis de vulnerabilidade associada à sua privatização, redução e categorização como doença, pois é considerada nefasta para o sujeito empreendedor de si próprio. As ideias de bem comum e comunidade estão associadas a uma outra forma de governo da vulnerabilidade, tendo também as suas problemáticas associadas. Seria importante refletir na reformulação do poder psiquiátrico, em que estes pressupostos já têm sido invocados, nomeadamente quando se defende uma intervenção psiquiátrica comunitária ${ }^{19}$ ou 0 tratamento em comunidades terapêuticas20, e de que forma esta mudança permite um governo da vulnerabilidade que seja dissidente, propondo uma alternativa ao modelo prevalente, ou equívoco, absorvendo um discurso que mantém e justifica as práticas centradas na responsabilização individual, abrangendo todos os aspectos da vida do sujeito, sendo inclusivamente realizado no local onde vive, e estando associado à construção do que é considerado social e politicamente como o bom sujeito e a boa comunidade.

$19 \mathrm{Na}$ qual é defendida o tratamento na comunidade, promovendo a integração da pessoa doente, envolvendo uma equipa constituída por terapeutas e técnicos de diferentes áreas (por exemplo, psiquiatria, psicologia e serviço social).

20 Baseadas em princípios considerados democráticos, nas ideias de responsabilidade, cidadania e empoderamento, em que a pessoa doente deve participar nos processos de decisão e na organização da comunidade. 


\section{Considerações Finais}

Procurou-se neste artigo articular as contribuições da filosofia com a psiquiatria e apontar outras formas de governo da vulnerabilidade. Alasdair MacIntyre e Michel Foucault são autores com perspectivas diferentes sobre o sujeito e o seu governo. Enquanto Alasdair MacIntyre concebe o ser humano numa perspectiva teleológica, que deve florescer em determinada comunidade, Michel Foucault analisa o sujeito como resultado de tecnologias de dominação, de saber-poder, que não são alheias ao próprio sujeito, mas às quais este adere e transforma, modificando-se e recriandose através do seu próprio poder e resistência. Contudo, se Alasdair MacIntyre concilia uma ética das virtudes com uma filosofia política de resistência ao poder institucionalizado, também Foucault, nas suas últimas entrevistas, defende uma ética da existência, recuperando a ética do cuidado de si da antiguidade grega, que levaria o sujeito a procurar ter uma vida boa e deixar os outros ter uma vida boa.

O dispositivo psiquiátrico, enquanto forma de governo da vulnerabilidade, inscreve-se em tecnologias de poder disciplinar e biopolítico, que têm em vista a segurança e a racionalidade econômica, em que a intervenção de medidas de prevenção sobre toda a população permite a sinalização de pessoas em risco, que devem ser tratadas de forma a recuperar a sua funcionalidade e produtividade. A classificação do sujeito em categorias diagnósticas associadas ao trauma põe em evidência a relação entre acontecimento, vulnerabilidade e doença, na qual a identificação do sujeito como vulnerável permite o seu reconhecimento e validação, inclusivamente econômica.

Contudo, este reconhecimento ocorre sob a marca da doença, está associado ao governo da vulnerabilidade como individual e privada, patologiza ou exclui formas não normativas de resposta ao trauma, assim como oculta situações violentas não associadas a doença. Se a vulnerabilidade pode ser contextualizada como negativa, situacional, privada, reservada a populações sujeitas a determinadas situações, neste artigo procura-se elaborar a vulnerabilidade como pertencente à condição humana, abertura ao outro, condição do seu reconhecimento e solidariedade.

Se vulnerabilidade não é necessariamente trauma, a vulnerabilidade possibilita que o trauma ocorra, e também o trauma pode ser pensado fora do dispositivo psiquiátrico, como ferida, apelo e possibilidade de criação. Não obstante, não se pretende romantizar as ideias de vulnerabilidade e trauma, defender um deixar sofrer (por oposição ao fazer viver da biopolítica, ou propor uma visão negativa da doença. A vulnerabilidade é simultaneamente potencialidade, resistência e possibilidade de impotência, fragilidade, sofrimento e doença, surgindo não como uma falta ou uma falha, mas como condição da existência. 


\section{Referências}

AMERICAN PSYCHIATRIC ASSOCIATION. Trauma and Stressor Related Disorders. Diagnostic and statistical manual of mental disorders. 5. ed. Washington: American Psychiatric Press, 2013. p. 265-290.

ARENDT, Hannah. A condição humana. Rio de Janeiro: Forense Universitária, 2007.

\section{ARISTOTLE. The nicomachean ethics. London: Penguin, 2004.}

BECK, Ulrich. Risk society: towards a new modernity. London: Sage Publications, 1992.

BUTLER, Judith. Frames of war. when is life grievable? London: Verso, 2009.

BUTLER, Judith. Rethinking vulnerability and resistance. In: BUTLER, Judith; GAMBETTI, Zeynep et al. (eds.). Vulnerability in resistance. Durham: Duke University Press, 2014. p. 12-27.

CAMPBELL, Timothy; SITZE, Adam. Biopolitics: an encounter. In: CAMPBELL, Timothy; SITZE, Adam (eds.). Biopolitics, a reader. Durham and London: Duke University Press, 2013.

CASTEL, Robert. From dangerousness to risk. In: BURCHELL, Graham; GORDON, Colin et al (Eds.). The Foucault effect. Chicago: The University of Chicago Press, 1991. p. 281-298.

DUNCAN, Whitney L. Gendered trauma and its effects. In: HINTON, Devon E.; GOOD, Byron J. (eds.). Culture and PTSD: trauma in global and historical prespective. Philadelphia: University of Pennsylvannia Press, 2016. p. 202-239.

ESPOSITO, Roberto. Communitas: the origin and destiny of community. Stanford, California: Stanford University Press, 2010.

ESPOSITO, Roberto. Immunization and violence. In: FORDHAM UNIVERSITY PRESS. Terms of the political: community, immunity, biopolitics. New York: Fordham University Press, 2013. p. 57-66.

FASSIN, Didier; RECHTMAN, Richard. The empire of trauma. Princeton, New Jersey: Princeton University Press, 2009.

FOUCAULT, Michel. Histoire de la sexualité 1. La volonté de savoir. Paris: Éditions Gallimard, 1976.

FOUCAULT, Michel.História da loucura na idade clássica. São Paulo: Perspectiva, 2005.

FOUCAULT, Michel. Psychiatric power: lectures at the college de France, 197374. Houndmills, Basingstoke, Hampshire: Palgrave Macmillan, 2008.

FOUCAULT, Michel. Security, territory, population, lectures at the college de France, 1977-1978. Houndmills, Basingstoke, Hampshire: Palgrave Macmillan, 2009.

FOUCAULT, Michel. Society must be defended: lectures at the collège de France, 1975-1976. London: Penguin Books, 2004.

FOUCAULT, Michel. Technologies of the self. In: RABINOW, Paul (ed.). Ethics: subjectivity and truth. New York: New Press, 1997. p. 223-252 (The essential works of Michel Foucault 1954-1984) 
FOUCAULT, Michel. The birth of biopolitics: lectures at the Collège de France 1978-1979. New York: Palgrave Macmillan, 2010.

FREUD, Sigmund. Para além do princípio do prazer. Lisboa: Relógio D'Água, 2009.

GILSON, Erinn C. The ethics of vulnerability: a feminist analysis of social life and practice. New York: Routledge, 2016.

HARDT, Michael; NEGRI, Antonio. Assembly. New York: Oxford University Press, 2017.

HARDT, Michael; NEGRI, Antonio. Commonwealth. Cambridge, Massachusetts: The Belknap Press of Harvard University Press, 2009.

HARDT, Michael; NEGRI, Antonio. Empire. Cambridge, Massachusetts: Harvard University Press, 2000.

HARDT, Michael; NEGRI, Antonio. Multitude: war and democracy in the age of empire. New York: The Penguin Press, 2004.

HARVEY, David. The creation of the urban commons. In: VERSO (ed.), Rebel cities: from the right to the city to the urban revolution. London, 2012. p. 6788.

LEVINAS, Emmanuel. Autrement qu'être ou au-delà de l'essence. Paris: Kluwer Academic, 1978.

LEVINAS, Emmanuel. Totalidade e infinito. Lisboa: Edições 70, 2018.

MACINTYRE, Alasdair. After virtue. London: Bloomsbury, 2011.

MACINTYRE, Alasdair. Dependent rational animals: why human beings need virtues. Chicago and La Salle, Illinois: Carus Publishing Company, 1999.

MACINTYRE, Alasdair. Politics, Philosophy and the Common Good. In: UNIVERSITY OF NOTRE DAME PRESS (Ed.). The macIntyre reader. Notre Dame, Indiana: University of Notre Dame Press, 1998. p. 235-252.

RICOEUR, Paul. Autonomie et vulnérabilité. In: LE JUSTE 2. Paris: Éditions Esprit, 2001. p. 85-106.

RICOEUR, Paul. Responsabilité et fragilité. Autres temps. Cahiers d'éthique sociale et politique, n. 76-77, p. 127-141, 2003.

RICOEUR, Paul. Soi-même comme un autre. Paris: Éditions du Seuil, 1990.

RORTY, Richard. Solidarity. In: Contingency, irony, and solidarity.

Cambridge: Cambridge University Press, 1989. p. 189-198.

VERMEULEN, Pieter. The biopolitics of trauma. In: BUELENS, Gert; DURRANT, Sam et al. (Ed.). The future of trauma theory. New York: Routledge, 2014. p. 141-155.

YOUNG, Allan. The harmony of illusions: inventing post-traumatic stress

disorder. Princeton, New Jersey: Princeton University Press, 1995. 